\title{
Study on the rainfall-flood relationship and related occurrence probability in Tongzhou Area
}

\author{
${ }^{a}$ C.Y. WANG \& M. ZANG\& Y.J. WANG, ${ }^{b}$ L.H. YANG \\ aBeijing hydrological centre, Beijing, China \\ ${ }^{b}$ Yunnan academy of scientific and technical information, Kunming, China
}

KEYWORD: Beiyunhe River; rainfall-flood relationship; Occurrence probability; Tongzhou Area ABSTRACT: More and more people are concerned about flood control and disaster mitigation. Beiyun River, as one of five river systems in Beijing, its flood control capacity play a critical role in urban flood control and disaster mitigation. Hence, the research on the relationship between the Beiyun River's rainfall and floods occurring has significance for flood control and disaster mitigation in Tongzhou area, Beijing. In this paper, Beiyun River (Tongzhou area basin) was selected as the research object, the rainfall-flood relationship, the occurrence probability of heavy rainfall and lager flood were studied with the method of mathematical statistics and theoretical analysis. The results showed based on the SPSS analysis, while the 24-hour rainfall was larger than $50 \mathrm{~mm}$, the occurrence probability that flow rate $>150 \mathrm{~m}^{3} / \mathrm{s}$ was 0.30 . Among them, the occurrence probability that flow rate ranged $150-500 \mathrm{~m}^{3} / \mathrm{s}, 500-1000 \mathrm{~m}^{3} / \mathrm{s}$ and $>1000 \mathrm{~m}^{3} / \mathrm{s}$ was $0.26,0.09$ and 0.30 , respectively. While the flow rate was larger than $150 \mathrm{~m}^{3} / \mathrm{s}$, the occurrence probability that 24-hour rainfall $>50 \mathrm{~mm}$ was 0.34 . Among them, the occurrence probability that 24 -hour rainfall ranged 50 $100 \mathrm{~mm}, 100-200 \mathrm{~mm}$ and $>200 \mathrm{~mm}$ was $0.20,0.13,0.02$, respectively. Based on $\mathrm{R}$ statistical programing, while flood peak flow rate was larger than $150 \mathrm{~m} 3 / \mathrm{s}$, the occurrence probability that 24-hour rainfall $>50 \mathrm{~mm}$ ranged from 0.28 to 0.45 ; while flood peak flow rate was larger than 150 $\mathrm{m} 3 / \mathrm{s}$, the occurrence probability that 24 -hour rainfall $<50 \mathrm{~mm}$ ranged from 0.54 to 0.70 ; while flood peak flow rate was less than $150 \mathrm{~m}^{3} / \mathrm{s}$, the occurrence probability that 24-hour rainfall $>50$ mm ranged from 0.45 to 0.68 ..

\section{INTRODUCTION}

The flood control and disaster mitigation is a hot issue for the contemporary society, academia. The Floods not only cause huge losses of the social economy, but also threaten the people life and health (Lu et al. 2010). In recent years, the flood disasters occurred frequently by rain in the national regional. As an international metropolis, Beijing is also face to the crisis. During the 2004-2012 years, the extreme rainfall weather occurred 42 times in Beijing, which took place 29 times in the city. The flood affected by many factors, the rainfall is the main factor. Due to heavy rains caused flooding events frequently during the Beijing flood season, how to reduce the flood and water-logging events have become the key problem need to be solved.

The existing researches mainly concentrated on urban rainstorm partition and rainstorm center variation (Mou. 2011), flood generation mechanism and risk assessment (Zhang et al. 2010; Hu et al. 2013; Yin et al, 2010), heavy rains flood trend analysis (Fan. 2011; Guan et al. 2006), rainfall - runoff relation ( $\mathrm{Li}$ et al. 2012; Yang, 2007), etc. The researches about the relationship and probability between for regional rainfall and flood were relative lacking. Hence, in order to solve this situation.

Therefore, this paper aiming at the problem of frequent heavy rains caused flooding events during flood season. Taking the Beiyun River basin in Tongzhou area as the research object, the rainfallflood relationship and the flood occurring probability were analyzed based on the measured data of hydrological stations (1919-2012) in Tongzhou area. It could provide technical supports for the urban flood control and disaster mitigation. 


\section{GENERAL SITUATION}

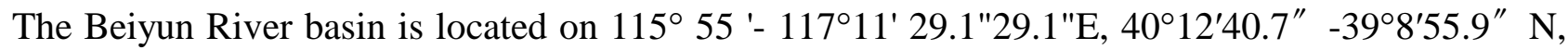
which originated from Hezijian village, Liucun town, Changping district, Beijing. Inflows into the next higher level in Hebei district of Tianjin. The total river length is $244 \mathrm{~km}$, the total basin area is $4247 \mathrm{~km}^{2}$, which includes Beiyun River and Wenyu River. The Wenyu River originated from Hezijian village, Liucun town. The river length is $97.5 \mathrm{~km}$, the basin area is $2518 \mathrm{~km}^{2}$. The Beiyun river originated from Xinjian village, Tongzhou town, The river length is $40.49 \mathrm{~km}$, the basin area is $1729 \mathrm{~km}^{2}$.

The Tongzhou hydrological station located in Beiguanzha, Tongzhou district, which is the controlling station For Beiyun River and Yunchaojian River. The river basin area is $2815 \mathrm{~km}^{2}$. As one of important hydrological stations in our country which undertakes the water level, flow, precipitation, evaporation, water quality, sediment, water temperature and other 14 observation items. During the period of observation, the history largest measured peak flow is $2200 \mathrm{~m}^{3} / \mathrm{s}$ (July 27, 1939), The largest annual rainfall is $1177.3 \mathrm{~mm}(1955)$.

\section{RAINFALL-FLOOD ANALYSIS}

\section{Historic precipitation analysis}

The historic precipitation of Tongzhou area was analyzed based on the actual measured precipitation data from 1919 to 2012 of Tongzhou hydrological stations, as shown in Figure 1. The results showed that annual average rainfall was $604 \mathrm{~mm}$ and little bigger than the annual average rainfall in Beijing $(585 \mathrm{~mm})$. Among them, the biggest precipitation was $1177 \mathrm{~mm}$ occurred in 1955 , and greater than $1170 \mathrm{~mm}$ encountered in 100 years. The minimum value occurred in 1999 which value is $263 \mathrm{~mm}$. Trend analysis was carried out on the precipitation series for many years, as shown in figure 2. During 94 years, the precipitation presented abundant-withered alternative variations. The anunal precipitation for years showed the slow decreasing tendency. Among them, the precipitation during 1999 to 2010 was less than the annual average rainfall for years, occurring hemiplegia phenomenon for the 12 years period.

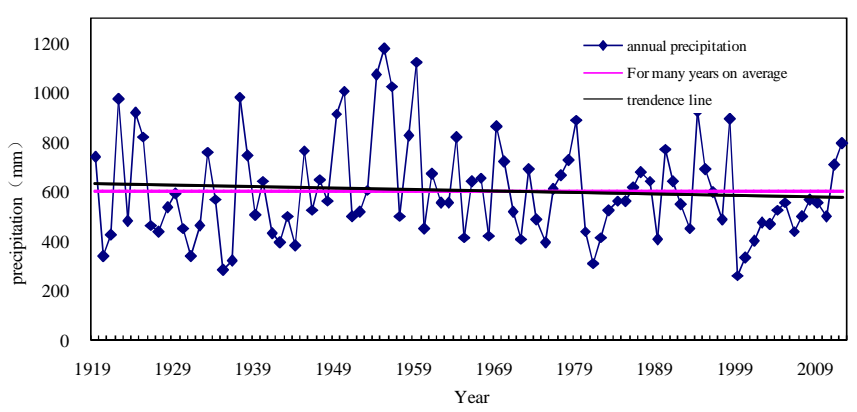

Figure1. The precipitation analysis between 1919 and 2012

The correlation analysis of rainfall-flood for many years

Based on the actual measurement data for 94 years (from 1919 to 2012), the correlation analysis of rainfall-flood was analyzed by Statistical software SPSS. The rainfall- flow linear relationship for many years was analyzed, as shown in Figure 2.The results showed that the linear relationship model is $y=0.881 x-126.05$. But the data points distribution around the linear model was relative sparse. The calculated correlation coefficient $\mathrm{R}^{2}$ was just 0.187 . It further explained that the linear relationship between rainfall-flood was not obvious. 


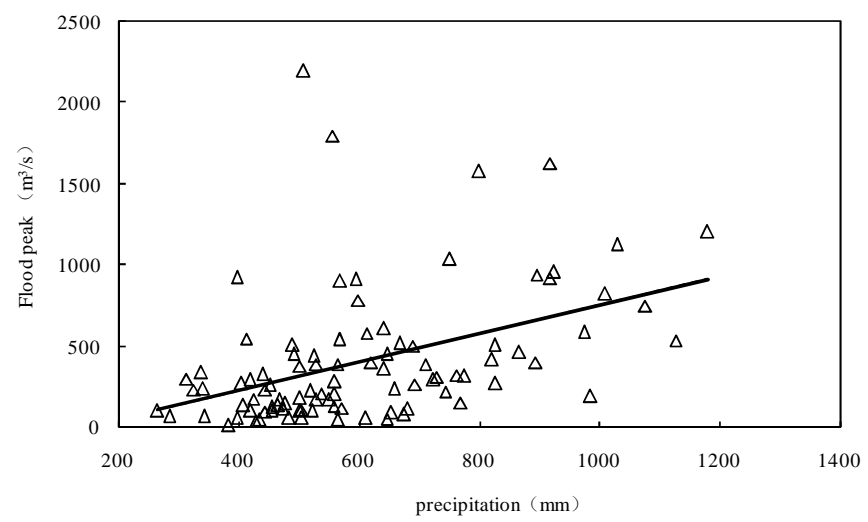

Figure2. The relationship of precipitation and flood peak for many years

\section{The correlation analysis of typical session rainfall-flood}

The rainfall-flood correlation analysis was studied from two aspects, the sample data was selected from two parts. One part of the sample data was selected from the precipitation data. In accordance with "the flood control manual" (Yang. 2014), as the cumulative rainfall of 24 hours was more than $50 \mathrm{~mm}$, it could be defend as the heavy rain. Hence, selected the rainfall of $24 \mathrm{~h}$ that more than 50 mm during 94 years as sample data, and the corresponding flow was also collected at the same time. The other part of the sample data was selected according to the experience method. Session flow more than $150 \mathrm{~m}^{3} / \mathrm{s}$ was selected as sample data, and the corresponding flow also selected.

(1) SPSS statistical analysis

Using SPSS software, the selected two groups of sample data were studied by correlation analysis respectively, the results showed in the Figure 3-4, the session precipitation more than $50 \mathrm{~mm}$ corresponding flow relation model was $y=2.629 x+0.292$, the correlation coefficient $\mathrm{R}^{2}$ is 0.0987 . The results showed that the $24 \mathrm{~h}$ precipitation more than $50 \mathrm{~mm}$ corresponding flow relation was not obvious. Session flow rate more than $150 \mathrm{~m}^{3} / \mathrm{s}$ corresponding rainfall relationship model was $y=0.003 x+50.930$. The correlation coefficient $\mathrm{R}^{2}$ was 0.0002 . The relationship was more irrelevant.

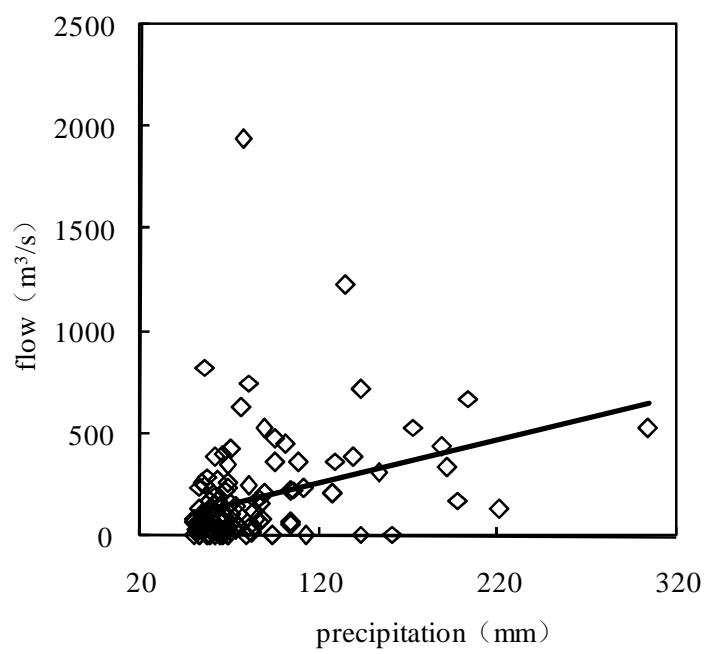

Figure3. The relationship of precipitation and flow

(Precipitation more than 50mm) 


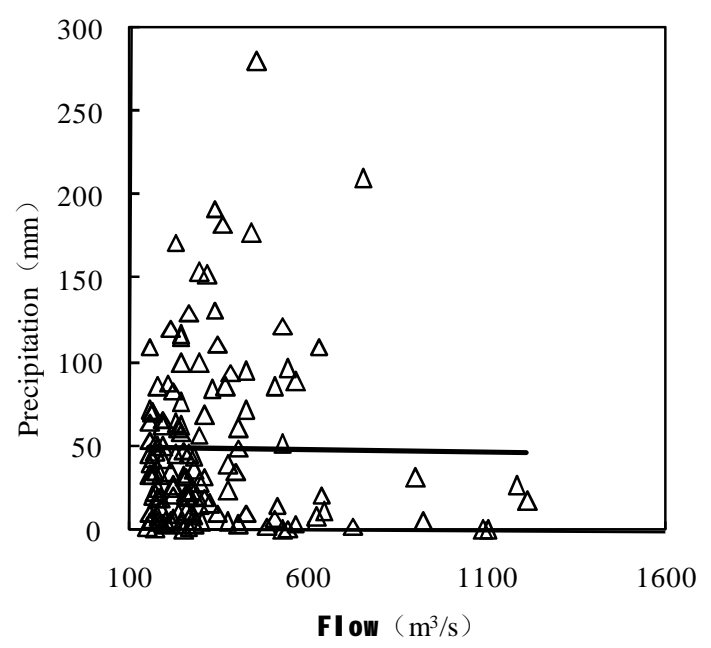

Figure4. The relationship of precipitation and flow

(Flow more than $150 \mathrm{~m}^{3} / \mathrm{s}$ )

(2) R statistical analysis

In order to further prove the relationship between rainfall and flow of Beiyun basin in Tongzhou area, the sample data is divided into four categories:

a. Peak flow $>150 \mathrm{~m}^{3} / \mathrm{s}$, Precipitation $>50 \mathrm{~mm}$, defined as $\mathrm{PF}>150 \mathrm{P}>50$;

b. Peak flow $>150 \mathrm{~m}^{3} / \mathrm{s}$, Precipitation $<50 \mathrm{~mm}$, defined as $\mathrm{PF}_{>150} \mathrm{P}<50$;

c. Peak flow $<150 \mathrm{~m}^{3} / \mathrm{s}$, Precipitation $>50 \mathrm{~mm}$, defined as $\mathrm{PF}_{<150} \mathrm{P}_{>5} 0$;

d. Peak flow $<150 \mathrm{~m}_{3} / \mathrm{s}$, Precipitation $<50 \mathrm{~mm}$, defined as $\mathrm{PF}_{<150} \mathrm{P}_{<50}$;

Due to the amount of data was only one for category d, which did not have repeatability. So data of $\mathrm{PF}_{<150} \mathrm{P}_{<50}$ exclusion. Strives for the corresponding correlation coefficient for other types of sorting data.

The correlation coefficient was defined as follows:

$$
\rho=\frac{\sum_{i=1}^{n}\left(x_{i}-\bar{x}\right)\left(y_{i}-\bar{y}\right)}{\sqrt{\sum_{i=1}^{n}\left(x_{i}-\bar{x}\right)^{2} \sum_{i=1}^{n}\left(y_{i}-\bar{y}\right)^{2}}}
$$

The correlation coefficient values between -1 to $1,|\rho|=0$ showed the $X, Y$ was uncorrelated; $|\rho|=1$ showed the $X, Y$ was correlated A with linear function relationship between $X$ and $Y$; As $|\rho|<1$, Changes in the $X$ caused part of $Y$ variation, the absolute value of $|\rho|$ was the greater, Changes in the $\mathrm{X}$ caused the greater changes in $\mathrm{Y} .|\rho| \geq 0.8$ was known as highly correlated, $0.5 \leq|\rho|<0.8$ was known as the significant correlation, $0.3 \leq|\rho|<0.5$ was known as low-grade related, $|\rho|<0.3$ was known as no relevant .

From the correlation coefficient analysis table 1, which can be showed: As the peak flow was small $\left(<150 \mathrm{~m}^{3} / \mathrm{s}\right)$, the precipitation $(<50 \mathrm{~mm})$ and peak flow $\left(>150 \mathrm{~m}^{3} / \mathrm{s}\right)$ correlation coefficient was negative, and the value was low. Hence, the quantity of rainfall had no obvious correlation. As the precipitation $\left(>50 \mathrm{~mm}\right.$ ) and peak flow $\left(>150 \mathrm{~m}^{3} / \mathrm{s}\right)$, the correlation coefficient was positive, but belonged to the low correlation. 
Table 1. Correlation coefficient of different category

\begin{tabular}{|c|c|c|}
\hline $\begin{array}{l}\text { preeipitation } \\
\text { Flood peak }\end{array}$ & $>50 \mathrm{~mm}$ & $<50 \mathrm{~mm}$ \\
\hline$>150 \mathrm{~m}^{3} / \mathrm{s}$ & 0.4 & -0.25 \\
\hline$<150 \mathrm{~m}^{3} / \mathrm{s}$ & 0.045 & - \\
\hline
\end{tabular}

\section{PRECIPITATION, FLOOD FREQUENCY ANALYSIS}

\section{SPSS statistical analysis}

Based on the above analysis, the relationship between rainfall and flow rate was not obvious for Tongzhou area. In this paper, the history long series data analyzed by classification. Mainly divided into the following three categories:

(1) Rainfall is heavier corresponding higher flow;

(2) Rainfall is heavier corresponding lower flow;

(3) Rainfall is lower corresponding higher flow. Each type of probability were discussed and research separately.

The Figure 5- 6 showed that when the $24 \mathrm{~h}$ precipitation was greater than $50 \mathrm{~mm}$, the flow $(<150$ $\left.\mathrm{m}^{3} / \mathrm{s}\right)$ occurring probability was less than the occurring probability of flow production $\left(>150 \mathrm{~m}^{3} / \mathrm{s}\right)$. When the flow rate was more than $150 \mathrm{~m}^{3} / \mathrm{s}$, The occurring probability of precipitation $(<50 \mathrm{~mm})$ was more than the occurring probability of precipitation $(>50 \mathrm{~mm})$.

Through the $24 \mathrm{~h}$ precipitation $(>50 \mathrm{~mm})$ sample data analysis calculation, the $24 \mathrm{~h}$ precipitation $(>50 \mathrm{~mm})$ caused the occurring probability of flow $\left(>150 \mathrm{~m}^{3} / \mathrm{s}\right)$ was 0.37 , which was less than 0.63 occurring probability of flow $\left(<150 \mathrm{~m}^{3} / \mathrm{s}\right)$. According to the experience method, the more than $150 \mathrm{~m}^{3} / \mathrm{s}$ peak flow was divided into three kinds of situation: $150-500 \mathrm{~m}^{3} / \mathrm{s}, 500$ $1000 \mathrm{~m}^{3} / \mathrm{s},>1000 \mathrm{~m}^{3} / \mathrm{s}$. The more than $50 \mathrm{~mm}$ precipitation are calculated respectively in the $24 \mathrm{~h}$ which happened three flow interval probability, the probability calculation results were $0.26,0.09$ and 0.30 respectively.

Through the flow rate $\left(>150 \mathrm{~m}^{3} / \mathrm{s}\right)$ sample data analysis calculation, when flow rate was more than $150 \mathrm{~m}^{3} / \mathrm{s}$, the occurring probability of $24 \mathrm{~h}$ rainfall $(>50 \mathrm{~mm})$ was 0.34 , the occurring probability of rainfall $(<50 \mathrm{~mm})$ was 0.66 . The $24 \mathrm{~h}$ precipitation of more than $50 \mathrm{~mm}$ was divided into three kinds: $50-100 \mathrm{~mm}, 100-200 \mathrm{~mm},>200 \mathrm{~mm}$. Calculated three kinds respectively when the flow rate was more than $150 \mathrm{~m}^{3} / \mathrm{s}$, the occurring probability of the three kinds of precipitation was 0.20 , 0.13 and 0.02 respectively.

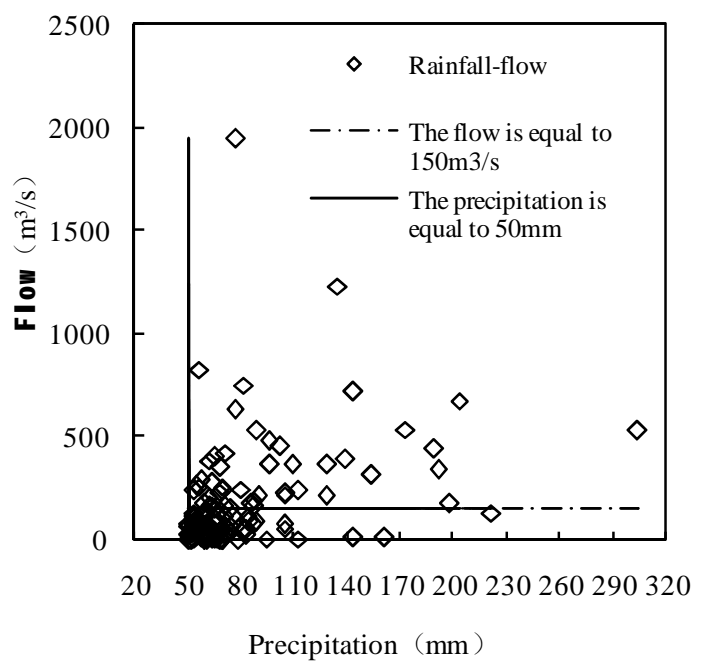

Figure5. The flood occurrence probability

(Precipitation more than 50mm) 


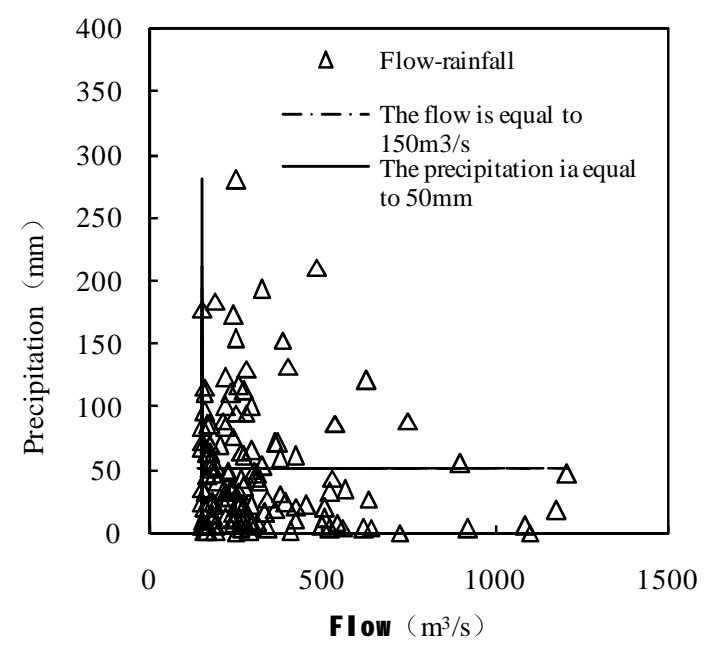

Figure6. The flood occurrence probability (Flow more than $150 \mathrm{~m}^{3} / \mathrm{s}$ )

\section{R statistical analysis}

Based on the measured data in the long history series, the two sample data points were analyzed by Chi square test (the original hypothesis is 0.5 ). They were also divided into three kinds. The three kinds were: (1) Peak flow $>150 \mathrm{~m}^{3} / \mathrm{s}$, Precipitation $>50 \mathrm{~mm}$, defined as $\mathrm{PF}_{>150 \mathrm{P}>50}$; (2)Peak flow $>$ $150 \mathrm{~m}^{3} / \mathrm{s}$, Precipitation $<50 \mathrm{~mm}$, defined as $\mathrm{PF}_{>150} \mathrm{P}_{<50}$; (3)Peak flow $<150 \mathrm{~m}^{3} / \mathrm{s}$, Precipitation $>$ $50 \mathrm{~mm}$, defined as $\mathrm{PF}_{<150} \mathrm{P}<50$.

The flow of more than $150 \mathrm{~m}^{3} / \mathrm{s}$ and the rainfall of more than $50 \mathrm{~mm}$ were defined as two samples respectively ( sample A and sample B). First, the sample A was divided into two kinds: (1)Peak flow $>150 \mathrm{~m}^{3} / \mathrm{s}$, Precipitation $>50 \mathrm{~mm}$; (2)Peak flow $>150 \mathrm{~m}^{3} / \mathrm{s}$, Precipitation $<50 \mathrm{~mm}$. At the same time, the two kinds were defined respectively. The definition codes were 1 and 0 . Using the above method defined sample B data, the Peak flow $<150 \mathrm{~m}^{3} / \mathrm{s}$, Precipitation $>50 \mathrm{~mm}$ is defined as code 1.

According to the definition of sample A, B data, the occurring probability was analyzed by using $\mathrm{R}$ statistical. The original assume their respective probability was 0.5 , then the data were analyzed by the binomial test, the results as follows:

(1) $\mathrm{PF}>150, \mathrm{P}>50$

The source codes were input in the $\mathrm{R}$ statistical, the occurring probability was calculated and analyzed under the condition of the credibility $95 \%$ which got a confidence interval for [0.28, 0.45]. It illustrated there are $95 \%$ sure real probability between 0.28 and 0.45 . So,it concluded that the occurring probability of $\mathrm{PF}>150, \mathrm{P}>50$ was between 0.28 and 0.45 in Tongzhou area.

(2) $\mathrm{PF}>150, \mathrm{P}<50$

The source codes were input in the $\mathrm{R}$ statistical, the occurring probability was calculated and analyzed under the condition of the credibility $95 \%$ which got a confidence interval for [0.54, 0.70]. It illustrated there are $95 \%$ sure real probability between 0.54 and 0.70 . So, it concluded that the occurring probability of $\mathrm{PF}>150 \mathrm{P}<50$ was between 0.54 and 0.70 in Tongzhou area.

(3) $\mathrm{PF}<150, \mathrm{P}>50$

The source codes were input in the R statistical, the occurring probability was calculated and analyzed under the condition of the credibility $95 \%$ which got a confidence interval for $[0.45,0.68]$. It illustrated there are $95 \%$ sure real probability between 0.45 and 0.68 . So, it concluded that the occurring probability of $\mathrm{PF}<150 \mathrm{P}>50$ was between 0.45 and 0.68 in Tongzhou area. 


\section{CONCLUSION}

Through the long history series data of rainfall and peak flow analysis (1919-2012) in the Tongzhou, the relationship and the occurrence probability of rainfall and flow for Tongzhou area were studied. The main draw the following conclusions:

(1) Analyzed the relationship of the history long series data of rainfall and peak flow by two kinds of mathematical statistical, the relationship between rainfall and flood peak was not obvious.

(2) Through studying the occurrence probability of rainfall and flood peak flow that showed when $24 \mathrm{~h}$ rainfall was more than $50 \mathrm{~mm}$ the occurrence probability of flow $\left(>150 \mathrm{~m}^{3} / \mathrm{s}\right)$ was 0.3 by statistical analysis. When flow rate is more than $150 \mathrm{~m}^{3} / \mathrm{s}$, the occurrence probability of flow (150-500 $\mathrm{m}^{3} / \mathrm{s}, 500-1000 \mathrm{~m}^{3} / \mathrm{s}$ and $>1000 \mathrm{~m}^{3} / \mathrm{s}$ ) was $0.26,0.09$ and 0.30 respectively. The probability of $24-$ hour rainfall of more than $50 \mathrm{~mm}$ was 0.34 . The precipitation occurrence probability of $50 \sim 100$ $\mathrm{mm}, 100 \sim 200 \mathrm{~mm}$, more than $200 \mathrm{~mm}$ was 0.20 , 0.13 and 0.02 respectively.

3. By the R mathematical statistical, in the Tongzhou area the occurrence probability of Peak flow > $150 \mathrm{~m}^{3} / \mathrm{s}$, precipitation $>50 \mathrm{~mm}$ was between 0.28 and 0.45 ; the occurrence probability of Peak flow $>150 \mathrm{~m}^{3} / \mathrm{s}$, precipitation $<50 \mathrm{~mm}$ was between 0.54 and 0.70 ; the occurrence probability of Peak flow $<150 \mathrm{~m}^{3} / \mathrm{s}$, precipitation $>50 \mathrm{~mm}$ was between 0.45 and 0.68 .

\section{REFERENCE}

1) Lu M, Liu M, Quan R.S, et al.2010. Analysis of system characteristics and vulnerability of rainstorm hazards in Shanghai. Journal of East China Norm al University (Natural Science) 2:9-15

2) Mou J.L. 2011. Analyzed on the designing storm hyetograph in Beijing. Lanzhou university

3)Zhang w, Li S.M, Zhu L.S. 2013. Effect Mechanism of Urban rainstorm waterlogging Formation in China. Urban Development Studie 1:122- 124

4) Hu H.B, Xuan C.Y, Zhu L.S. 2013. The Pre-event Risk Assessment of Beijing Urban Flood. Journal of applied meteorological science 24(1):99- 108.

5) Yin Z.N, Xu S.Y, Yin J. 2010. Small-scale Based Scenario Modeling and Disaster Risk Assessment of Urban Rainstorm Water-logging. Acta geographica sinica 65(5):553-562

6) Fan Z.H. 2011. Analyzed on rainfall trendence and Studied the storm hyetograph in Tianjin. TianjinUniversity

7) Guan T.S, Wang J.Q. 2006. Inter-decadal change of the rainstorm and flood extreme values in the 20th century. Advances in water science 17 (1): 89-94

8) Li Z.J, Yu, S.S, Li Q.L, et al. 2012. Regional pattern of rainfall-runoff relationship. Journal of Hohai University( Natural Sciences) 40(6):597-604

9) Yang X.J. 2007. Analyzed on the influence factors of Rainfall runoff. Ground water 29(5):50-53

10) Yang Z.S .2014. The flood-controlling manual. Beijng hydrological centre 